\title{
Occurrence of odor problems in drinking water of major cities across China
}

\author{
Daolin SUN ${ }^{1}$, Jianwei YU (凶) ${ }^{1}$, Min YANG ${ }^{1}$, Wei AN ${ }^{1}$, Yunyun $Z_{H A O}{ }^{1}$, Ning $\mathbf{L U}^{2}$, \\ Shengguang YUAN ${ }^{1}$, Dongqing ZHANG ${ }^{1}$ \\ 1 State Key Laboratory of Environmental Aquatic Chemistry, Research Center for Eco-Environmental Sciences, \\ Chinese Academy of Sciences, Beijing 100085, China \\ 2 Shanghai National Engineering Research Center of Urban Water Resources Co., Ltd., Shanghai 200082, China
}

(C) Higher Education Press and Springer-Verlag Berlin Heidelberg 2013

\begin{abstract}
A comprehensive investigation into the occurrence of odor problem at 111 drinking water treatment plants (DWTPs) in major cities across China was undertaken using both flavor profile analysis (FPA) and gas chromatography-mass spectrometry (GC-MS). Eighty percent of source water samples exhibited odor problems, characterized by earthy/musty (41\%) and swampy/septic $(36 \%)$ odors, while the occurrence rate was lower $(45 \%)$ in the finished water. Source water from rivers exhibited more pollution-origin odors, such as the swampy/septic odor, while that from lakes and reservoirs exhibited more algaeorigin odors, such as earthy/musty odors. The occurrence rate of 2-methylisoborneol (2-MIB) in the surface source water samples was $75 \%$, with $7 \%$ of samples containing 2MIB concentrations of over $10 \mathrm{ng} \cdot \mathrm{L}^{-1}$. The earthy/musty odor in the lake/reservoir water samples was mainly caused by 2-MIB (linear regression coefficient, $R^{2}=0.69$ ), while the correlation between 2-MIB concentration and the earthy/musty odor intensity in the river-source water samples was weak $\left(R^{2}=0.35\right)$. These results will be useful for the management of odor-quality problems in drinking water of China.
\end{abstract}

Keywords flavor profile analysis, 2-methylisoborneol, swampy/septic odor, earthy/musty odor, drinking water quality

\section{Introduction}

Taste and odor ( $\mathrm{T} / \mathrm{O})$ problems have long been a major concern to the water industry, because public confidence

Received March 27, 2012; accepted June 4, 2013

E-mail: jwyu@rcees.ac.cn and acceptance of drinking water is largely influenced by aesthetics [1]. According to an investigation in the USA, 16 percent of a total of 377 utilities reported serious $\mathrm{T} / \mathrm{O}$ problems, and 43 utilities had experienced a $\mathrm{T} / \mathrm{O}$ event lasting for longer than one week [2]. At the same time, only sporadic reports of $\mathrm{T} / \mathrm{O}$ events in drinking water have been reported in China, particularly during the last ten years [35]. More clarity is needed regarding the overall occurrence of $\mathrm{T} / \mathrm{O}$ problems in China.

The sensory method of threshold odor number (TON) has been adopted widely to determine quality of water in terms of odor. The United States Environmental Protection Agency (USEPA) has established a secondary maximum contaminant level for drinking water odor quality with a TON of 3 [6], which has also been adopted by the European Union (EU) and Japan. However, TON does not provide specific descriptive information about odor, which is essential for the control of $\mathrm{T} / \mathrm{O}$ problems, since different types of odorous compounds may require different treatment technologies $[1,7]$. To overcome the disadvantages associated with the TON method, flavor profile analysis (FPA), which has the capacity to describe the odor characteristics and intensity of each descriptor, has recently been adopted for evaluating drinking water quality in the USA, the EU and some other countries [8,9]. A strict training procedure is required for FPA panelists to ensure reliable results $[10,11]$. Panelists must undergo substantial training to become familiar with the odor intensity scale and the commonly-used odor descriptors. This enables them to discern the odor and intensity of individual substances that comprise the overall odor of a sample [5]. Seven point scales, i.e., 1, 2, 4, 6, 8, 10 and 12, are usually applied, with the averaged values from all panelists being regarded as the odor intensity value. A previous study has suggested that an FPA intensity of 3.0 for a certain odor could be set as the acceptance level: for example, musty 
3.0 [9]. The odor problems in drinking water have now been categorized into eight groups according to the odor profile. The earthy/musty, swampy/septic and fishy odors are the most frequently encountered odor category in drinking water industry [12].

In this study, a survey of the odor occurrence in 111 Drinking Water Treatment Plants (DWTPs) was performed by means of the FPA and instrumental approaches. FPA was used to describe the odor characteristics. The levels of two earthy/musty odor compounds, i.e., 2methylisoborneol (2-MIB) and geosmin, were determined using gas chromatography-mass spectrometry (GC-MS). To the best of our knowledge, this is the first report on the occurrence of odor problems in the drinking waters of 34 major cities across China. The results will be useful for managing odors in drinking water.

\section{Material and methods}

\subsection{Sampling}

Source water (77) and finished water (111) samples were collected from a total of 111 DWTPs in 34 major cities in China from November 2009 to March 2010. Samples were refrigerated and transported to the laboratory in amber glass bottles (without headspace). Detailed information about the cities where samples were collected is shown in Table 1. An excess of sodium thiosulfate (Regent grade, Baker, USA) was added to the finished water samples to eliminate the masking effect of chlorine. Among the 111 DWTPs, $83 \%$ use surface waters, including 52 that source water from rivers and 40 that extract water from lakes/ reservoirs. The remaining 17\% relied on groundwater (19/ 111).

\subsection{Chemicals and materials}

Standard compounds including 2-methylisoborneol (2-
MIB), geosmin and 2-isobutyl-3-methoxy pyrazine (IBMP, as internal standard), were obtained from SigmaAldrich Co., USA. Stock solutions, at concetrations of 100 $\mu \mathrm{g} \cdot \mathrm{L}^{-1}$, were prepared by diluting standard solutions with ultra-pure water. $\mathrm{NaCl}$ of analytical grade was obtained from Beijing Chemicals Ltd., China and heated to $450^{\circ} \mathrm{C}$ for two hours before use.

\subsection{Odor evaluation}

Flavor profile analysis (FPA) was used for odor evaluation. A detailed description of the training and application associated with the FPA method can be found in the Standard Methods for Water and Wastewater [10]. In this study, the panel was made up of at least four panelists for each test. Seven-point scales of 1-12 were used to describe the intensity of samples. In each batch of samples, odor standard solutions of different intensities were used by the panel as references in terms of odor descriptors and intensities.

\subsection{Extraction of odorants}

Solid phase microextraction (SPME) was applied, as described in a previous study [13]. A fiber coated with a 30/50- $\mu \mathrm{m}$ divinylbenzene/carboxen/polydimethylsiloxene film (No.57348, Supelco, USA) was chosen for SPME extraction. The fiber was injected through a silicon-Teflon coated septum and placed into the headspace of a $75 \mathrm{~mL}$ extraction vial containing a $50 \mathrm{~mL}$ water sample. After adding $12.5 \mathrm{~g} \mathrm{NaCl}$ to the samples, the vials were maintained at a temperature of $65^{\circ} \mathrm{C}$, using a waterjacketed system. Extraction was performed for $30 \mathrm{~min}$ under mixing.

\subsection{GC-MS analysis}

Analysis of 2-MIB and geosmin was performed on a GCMS (HP 6890/5975, USA) equipped with a $30 \mathrm{~m}$-long

Table 1 Detailed information of sampling locations

\begin{tabular}{|c|c|c|c|c|c|}
\hline sampling city & sampling DWTP numbers & sampling city & sampling DWTP numbers & sampling city & sampling DWTP numbers \\
\hline Haikou & 2 & Lanzhou & 3 & Dalian & 4 \\
\hline Kunming & 2 & Nanjing & 3 & Fuzhou & 4 \\
\hline Nanchang & 2 & Ningbo & 3 & Guangzhou & 4 \\
\hline Qingdao & 2 & Shenyang & 3 & Hohhot & 4 \\
\hline Yinchuan & 2 & Shijiazhuang & 3 & Nanning & 4 \\
\hline Beijing & 3 & Taiyuan & 3 & Shanghai & 4 \\
\hline Changchun & 3 & Tianjin & 3 & Shenzhen & 4 \\
\hline Changsha & 3 & Xiamen & 3 & Xi'an & 4 \\
\hline Chengdu & 3 & Xining & 3 & Chongqing & 5 \\
\hline Harbin & 3 & Wuhan & 3 & Guiyang & 5 \\
\hline Hangzhou & 3 & Zhengzhou & 3 & Jinan & 5 \\
\hline Hefei & 3 & & & & \\
\hline
\end{tabular}


capillary column (HP-5, Agilent, USA) according to a previous study [5]. The SPME fiber was introduced directly into the injector for a three-minute exposure time. The SIM mode was used for the quantification of 2MIB and geosmin, quantitative ions of which were 95 and $112 \mathrm{~m} / \mathrm{z}$, respectively. The detection limits were 1.0 and $1.5 \mathrm{ng} \cdot \mathrm{L}^{-1}$ for 2-MIB and geosmin, respectively, and the recoveries ranged from $70 \%$ to $120 \%$ (median: $102 \%, n=$ 6 ) and from $93 \%$ to $120 \%$ (median: $106 \%, n=6$ ).

\section{Results and discussion}

3.1 Odor characterization for source water and finished water samples

Of the source water samples, $80 \%$ exhibited unpleasant odors with an average FPA intensity of 4.1 (as shown in

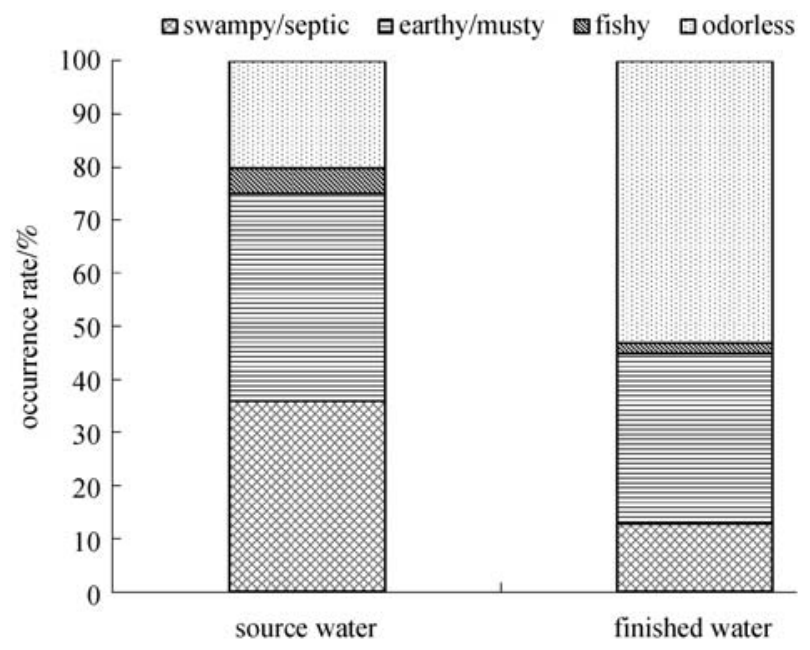

Fig. 1 Comparison of odor descriptors detected in source and finished waters
Fig. 1). The dominant odor characteristics were swampy/ septic (36\%), and earthy/musty (41\%). Compared with the source water samples, the finished water samples exhibited similar odor characteristics, with a reduced occurrence $(45 \%)$ and odor intensity (with an average of 2.8).

The FPA results for different source waters are shown in Table 2. For the samples collected from river sources, $91 \%$ exhibited odor problems. These were characterized by swampy/septic (54\%), earthy/musty (40\%) and fishy $(11 \%)$ odors. Average intensity values reached levels of 4.3 and 4.8 , for swampy/septic and fishy odors, respectively. On the other hand, lake/reservoir water samples exhibited predominantly earthy/musty (50\%) and swampy/ septic $(30 \%)$ odors, with average intensities of 3.4 and 4.8 , respectively. Groundwater samples had a lower occurrence rate (33\%) and average intensity (2.7), with the earthy/ musty odor being dominant. These results are similar to groundwater from the USA, where fewer odor problems have been reported [2].

The earthy/musty odor, normally caused by 2-MIB and geosmin, is frequently detected in surface waters around the world. This is produced mainly by cyanobacteria or actinomycetes $[14,15]$. Septic and swampy odors are usually the result of human influences: either directly due to wastewater dumpling, accidental spillage or agricultural runoff; or indirectly due to the excessive growth of odor producing aquatic organisms in eutrophic waters $[11,16]$. The caustic compounds that are responsible for the swampy/septic odor are more complicated. Certain sulfur-containing and nitrogen-containing compounds, such as dimethyl disulfide, dimethyl trisulfide and indole, have been considered to be the cause of some swampy/ septic odors $[5,16]$, while some amines (such as butanolamine and trimethylamine [17]) and some polyunsaturated fatty acid derivatives(such as 2,4-heptadienal, 2,4,7decatrienal and heptanal [14]) have been associated with fishy odors. In general, the earthy/musty and fishy odors

Table 2 Odor characteristics categorized by flavor profile analysis ${ }^{\text {a) }}$

\begin{tabular}{|c|c|c|c|c|c|}
\hline & \multirow[t]{2}{*}{ odor characteristics } & \multicolumn{2}{|c|}{ source water } & \multicolumn{2}{|c|}{ finished water } \\
\hline & & occurrence/\% & average intensity ${ }^{\mathrm{b})}$ & occurrence $/ \%$ & average intensity \\
\hline \multirow[t]{4}{*}{ river } & earthy/musty & 40 & 3.1 & 17 & 2.7 \\
\hline & swampy/septic & 54 & 4.3 & 29 & 2.1 \\
\hline & fishy & 11 & 4.8 & 5 & 3.8 \\
\hline & odorless & 9 & - & 50 & - \\
\hline \multirow[t]{4}{*}{ lake/ reservoir } & earthy/musty & 50 & 3.4 & 40 & 3.0 \\
\hline & swampy/septic & 30 & 4.8 & 15 & 2.6 \\
\hline & grassy & 3 & 3.6 & - & - \\
\hline & odorless & 30 & - & 45 & - \\
\hline \multirow[t]{2}{*}{ groundwater } & earthy/musty & 33 & 2.7 & 15 & 2.0 \\
\hline & odorless & 67 & - & 85 & - \\
\hline
\end{tabular}

Notes: a) 77 source water samples were investigated, including 35 river sources, 33 lake/reservoir sources and 9 groundwater sources; 111 finished water samples were investigated, including 52 river sources, 40 lake/reservoir sources and 19 groundwater sources; b) average FPA intensity for those samples in which the odor was detected 
Table 3 Summary of 2-MIB and geosmin in the source water and finished water

\begin{tabular}{|c|c|c|c|c|c|c|c|c|c|}
\hline & \multirow[t]{2}{*}{ compounds } & \multicolumn{4}{|c|}{ source water } & \multicolumn{4}{|c|}{ finished water } \\
\hline & & occu. $/ \%{ }^{\text {a) }}$ & $>5 \mathrm{ng} \cdot \mathrm{L}^{-1} / \%$ & $\max { }^{b)}$ & med. $^{\mathrm{c})}$ & occu. $/ \%$ & $>5 \mathrm{ng} \cdot \mathrm{L}^{-1} / \%$ & $\max$. & med. \\
\hline \multirow[t]{2}{*}{ river } & 2-MIB & 80 & 26 & 25.8 & 4.0 & 52 & 13 & 12.2 & 1.6 \\
\hline & geosmin & 57 & 6 & 6.1 & 1.6 & 44 & 5 & 6.2 & 1.1 \\
\hline \multirow[t]{2}{*}{ lake/res-ervoir } & 2-MIB & 69 & 45 & 65.0 & 5.8 & 67 & 40 & 32.5 & 5.3 \\
\hline & geosmin & 33 & 6 & 9.1 & 1.2 & 30 & 5 & 9.0 & 1.0 \\
\hline
\end{tabular}

Notes: a) occurrence rate; b) maximum concentration: $\mathrm{ng} \cdot \mathrm{L}^{-1}$; c) medium concentration: $\mathrm{ng} \cdot \mathrm{L}^{-1}$

are mainly produced by biological metabolites, while the swampy/septic odors generally originate from environmental pollution. We can thus conclude that the river water was dominated by pollution-origin odors, while the lake/ reservoir water was dominated by odors from an algal origin.

As shown in Table 2, the finished water samples exhibited a significantly reduced average intensity. Compared to the finished water samples from DWTPs receiving the river-type source water, which exhibited a significantly reduced occurrence rate of the earthy/musty odor (from $40 \%$ in source water to $17 \%$ in finished water), the occurrence rate in DWTPs that received lake/reservoirtype source water only changed slightly (from 50\% to $40 \%$ ). The reason for this is discussed below.

3.2 Occurrence of 2-MIB and geosmin in source water and finished water samples

Table 3 shows the occurrence of 2-MIB and geosmin in source water and finished water samples. The occurrence rates of 2-MIB in the river and lake/reservoir-type source water were $80 \%$ and $69 \%$, respectively. The median and maximum levels of 2-MIB in the lake/reservoir water samples (of 5.8 and $65.0 \mathrm{ng} \cdot \mathrm{L}^{-1}$, respectively) were much higher than those in the river samples (of 4.0 and $25.8 \mathrm{ng} \cdot \mathrm{L}^{-1}$, respectively). 2-MIB concentrations of above $5.0 \mathrm{ng} \cdot \mathrm{L}^{-1}$ were detected in $45 \%$ and $26 \%$ of the lake/ reservoir and river source water samples, respectively.

On the other hand, although gesomin was detected among $40 \%$ of the source water samples with medium concentrations of 1.6 and $1.2 \mathrm{ng} \cdot \mathrm{L}^{-1}$ for river and lake/ reservoir waters, respectively, the maximum concentration of $9.1 \mathrm{ng} \cdot \mathrm{L}^{-1}$ was still below the odor threshold value of $10 \mathrm{ng} \cdot \mathrm{L}^{-1}[18]$.

High concentrations of 2-MIB and geosmin are normally observed during warm seasons (summer and early autumn) when cyanobacteria grow rapidly $[19,20]$. For example, a peak 2-MIB concentration of approximately $170 \mathrm{ng} \cdot \mathrm{L}^{-1}$ was recorded in a northern reservoir in October 2005 [5]. In another reservoir, a peak geosmin concentration exceeding $7000 \mathrm{ng} \cdot \mathrm{L}^{-1}$ was detected in July, 2007 [21]. In the present study, sampling took place during the cold season, from November 2009 to March 2010. Although the results of this study do not represent the highest levels of 2-MIB in each source water, the relatively high detection rates and mean values suggest that 2-MIB may be a serious problem during warm seasons for many surface DWTPs. Among the 111 DWTPs, only five have adopted the ozone-biological activated carbon and powdered activated carbon (PAC) technologies that are effective for removing 2-MIB and geosmin [22-24]. So PAC dosing should be applied to those conventional DWTPs whose source water was detected with relatively high levels of 2-MIB. On the other hand, 2-MIB was also detected in a few groundwater samples at a relatively low concentration of below $6.0 \mathrm{ng} \cdot \mathrm{L}^{-1}$. This may originate from the exchange of surface water and groundwater.

As shown in Fig. 2, the relationship between the 2-MIB levels and the earthy/musty odor intensity in source water samples followed the Weber-Fechner model, which describes the relationship between odor intensities and odorant concentrations in water [25]. The correlation was more significant in the lake/reservoir-type source water samples $\left(R^{2}=0.69\right)$ than in the river-type source samples $\left(R^{2}=0.35\right)$. And for the investigations, there are many cases where no earthy/musty odor was detected in spite of the existence of 2-MIB (below $4.3 \mathrm{ng} \cdot \mathrm{L}^{-1}$ ), which may be due to that concentrations of 2-MIB in these samples were typically below the odor threshold concentration. On the other hand, there are some cases where earthy/musty odor intensity was as high as 4.0 although the detected 2-MIB

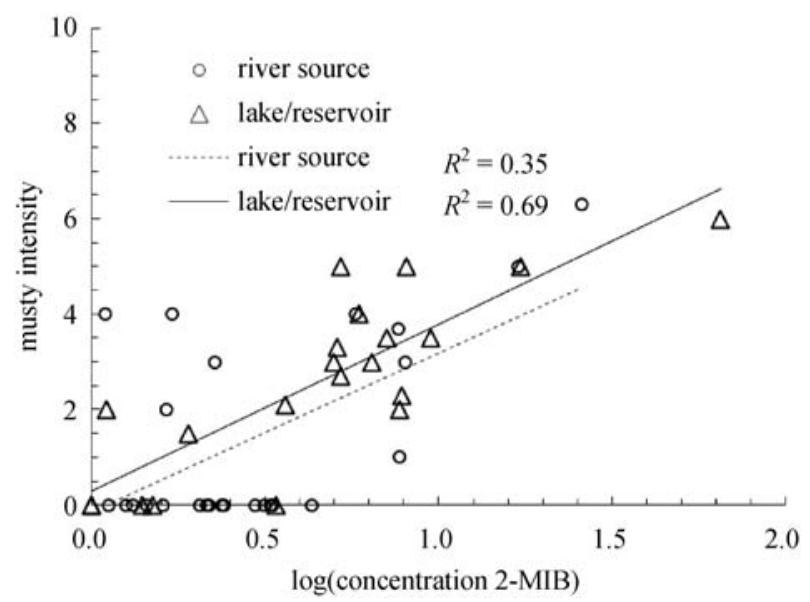

Fig. 2 Relationship between 2-MIB levels and intensity of earthy/musty odors in the source waters 
concentration was below $1.7 \mathrm{ng} \cdot \mathrm{L}^{-1}$. This suggests that other than 2-MIB and geosmin, some other earthy/musty odorants were probably present in the source water [12].

As shown in Table 2, the earthy/musty odor in DWTPs that depended on the river-type source water was more easily removed than the odors from DWTPs that depended on lake/reservoir-type source water. As discussed above, most of DWTPs have adopted conventional treatment processes, which are not effective for removing 2-MIB. So the earthy/musty odor in the lake/reservoir-type source water was difficult to be reduced since it was mainly caused by 2-MIB. By comparison, the earthy/musty odor in the river-type source water was slightly easier to be removed, suggesting that musty odorants other than 2-MIB are much more easily removed by conventional treatment technologies.

\section{Conclusions}

The results of the national survey showed that odor problems occurred extensively in surface source waters and finished waters of drinking water treatment plants. The river-type source water was dominated by pollution-origin odors, such as the swampy/septic odor, while the lake/ reservoir-type source water was dominated by algae-origin odors such as earthy/musty odors. 2-MIB was responsible for most of the earthy/musty odors found in DWTPs that extract water from lake/reservoir-type sources. The reasons for the earthy/musty odor in the river-type source water are more complicated. Since 2-MIB is not easily removed by conventional water treatment processes, powdered activated carbon is suggested for abating the earthy/musty odor problems.

\begin{abstract}
Acknowledgements This work was financially supported by the National Natural Science Foundation of China (Grant No. 50938007), the Funds for Major Science and Technology Program for Water Pollution Control and Treatment (No. 2009ZX07419-001) and the Key Scientific and Technological Projects of Science and Technology Commission of Shanghai Municipality (No. 12231201600). The authors would like to express their gratitude toward members from the water treatment plants for their assistance during sampling.
\end{abstract}

\section{References}

1. World Health Organization. Guidelines for drinking-water quality. World Health Organization, Geneva, Switzerland, 2011

2. Suffet I H, Corado A, Chou D, McGuire M J, Butterworth S. AWWA taste and odor survey. Journal - American Water Works Association, 1996, 88(4): 168-180

3. Yang M, Yu J, Li Z, Guo Z, Burch M, Lin T F. Taihu lake not to blame for Wuxi's woes. Science, 2008, 319(5860): 158

4. Zuo Y, Li L, Zhang T, Zheng L, Dai G, Liu L, Song L. Contribution of Streptomyces in sediment to earthy odor in the overlying water in Xionghe Reservoir, China. Water Research, 2010, 44(20): 6085-94
5. Yu J W, Zhao Y M, Yang M, Lin T F, Guo Z H, Gu J N, Li S, Han W. Occurrence of odour-causing compounds in different source waters of China. Journal of Water Supply: Research and Technology - Aqua, 2009, 58(8): 587-594

6. SEPA. Secondary drinking water regulations: guidance for nuisance chemicals. 816-F-10-079, 2011 Available at: water.epa.gov/drink/ contaminants/secondarystandards.cfm (access May 31, 2013)

7. McGuire M J. Off-flavor as the consumer's measure of drinking water safety. Water Science \& Technology, 1995, 31(11): 1-8

8. Krasner S W, McGuire M J, Ferguson V B. Tastes and odors: the flavor profile method. Journal - American Water Works Association, 1985, 77(3): 34-39

9. Suffet I H, Schweitze L, Khiari D. Olfactory and chemical analysis of taste and odor episodes in drinking water supplies. Reviews in Environmental Science and Biotechnology, 2004, 3(1): 3-13

10. APHA, AWWA, WEF. Standard Methods for the Examination of Water and Wastewater. 20th ed. Washington, D C: American Public Health Association, 2000

11. Omür-Ozbek P, Dietrich A M. Developing hexanal as an odor reference standard for sensory analysis of drinking water. Water Research, 2008, 42(10-11): 2598-2604

12. Suffet I H, Khiari D, Bruchet A. The drinking water taste and odor wheel for the millennium: beyond geosmin and 2-methylisoborneol. Water Science \& Technology, 1999, 40(6): 1-13

13. Lin T F, Wong J Y, Kao H P. Correlation of musty odor and 2-MIB in two drinking water treatment plants in South Taiwan. The Science of the Total Environment, 2002, 289(1-3): 225-235

14. Watson S B. Cyanobacterial and eukaryotic algal odour compounds: signals or by-products? A review of their biological activity. Phycologia, 2003, 42(4): 332-350

15. Zaitlin B, Watson S B. Actinomycetes in relation to taste and odour in drinking water: myths, tenets and truths. Water Research, 2006, 40(9): 1741-1753

16. Khiari D, Barrett S E, Suffet I H. Determination of organic compounds causing decaying vegetation and septic odors in drinking water by sensory GC. Journal - American Water Works Association, 1997, 89(4): 150-161

17. Herrmann V, Jüttner F. Excretion products of algae: Identification of biogenic amines by gas-liquid chromatography and mass spectrometry of their trifluoroacetamides. Analytical Biochemistry, 1977, 78(2): 365-373

18. Peter A, Köster O, Schildknecht A, von Gunten U. Occurrence of dissolved and particle-bound taste and odor compounds in Swiss lake waters. Water Research, 2009, 43(8): 2191-2200

19. Tung S C, Lin T F, Yang F C, Liu C L. Seasonal change and correlation with environmental parameters for 2-MIB in Feng-Shen Reservoir, Taiwan. Environmental Monitoring and Assessment, 2008, 145(1-3): 407-416

20. Westerhoff P, Rodriguez-Hernandez M, Baker L, Sommerfeld M. Seasonal occurrence and degradation of 2-methylisoborneol in water supply reservoirs. Water Research, 2005, 39(20): 48994912

21. Li Z L, Yu J W, Yang M, Zhang J, Burch M D, Han W. Cyanobacteial population and harmful metabolites dynamics during a bloom in Yanghe Reservoir, North China. Harmful Algae, 2010, 9 
(5): 481-488

22. Bruchet A, Duguet J P. Role of oxidants and disinfectants on the removal, masking and generation of tastes and odours. Water Science \& Technology, 2004, 49(9): 297-306

23. Nerenberg R, Rittmann B E, Soucie W J. Ozone/biofiltration for removing MIB and geosmin. Journal - American Water Works
Association, 2000, 92(12): 85-95

24. Jung S W, Baek K H, Yu M J. Treatment of taste and odor material by oxidation and adsorption. Water Science \& Technology, 2004, 49 (9): 289-295

25. Thiemer E T. Fragrance Chemistry: the Science of the Sense of Smell. New York: Academic Press, 1982 